\title{
LECTURERS' MOTIVATIONAL STRATEGY IN ESP CLASSROOM
}

\author{
Afif Ikhwanul Muslimin \\ UIN Mataram, afifikhwanulm@uinmataram.ac.id
}

\begin{abstract}
This study aimed to examine teachers' motivational strategies and their reasons for the employment of the strategies in English for Specific Purposes (ESP) classrooms at the Faculty of Dakwah dan Ilmu Komunikasi (FDIK), the Faculty of Preaching and Communication Sciences at the Mataram State Islamic University (UIN Mataram). This research employed descriptive qualitative design, which collected the data through interviews involving four English lecturers of ESP classes representing each program of study at the Faculty, namely Management of Dakwah (Preaching), Islamic Community Development, Islamic Counseling and Guidance, and Islamic Communication and Broadcasting. Drawing on the interview data, it was found that ESP teachers at FDIK UIN Mataram generally employed all Ten Commandments for motivating language learners proposed by Cheng and Dornyei (2007). Further, it was found that one of the lecturers applied interview strategy, though it does not belong to the Ten Commandments, it was stated in Cheng and Dörnyei (2007) as main instrument, that it promotes self-motivating learner strategy. Another finding also unveiled that the English lecturers deployed the motivational strategies because of (1) their being easier to practice, being more comfortable, and being more fun, (2) their affordances in developing the students' awareness on the future success, (3) their showing care on students' learning improvement and interest, and (4) their being fair and wise in assessment.
\end{abstract}

Keywords: Lecturers' motivational strategy, and ESP Classroom. 


\section{INTRODUCTION}

The field of teaching English in none English department generally known as English for Specific Purposes (ESP) has developed rapidly becoming a major part in English Language Teaching (ELT). English for Specific Purposes (ESP) refers to the teaching and learning certain language and skills required by specific learners for a particular purpose (Day \& Krzanowski, 2011). The students here do not learn English in general, but more focus on their needs as reflected to their field of study.

Many factors influence the success of ESP instruction. One of the important factors of teaching ESP is the teachers. In the context of teaching, it is better to consider a lecturer as the most experienced and well motivated person in a classroom setting. As common people, lecturers behave appropriately and adjust themselves in a provided environment. Eggleton (1992) mentioned that classroom is one of environments which may become the most demanding context for individuals' perceptions of their selfworth. Teaching experience and motivation in a classroom are quite important for the teachers because they know better how to lead the activity and decide proper strategies that meet with students' need. According to Bishay (1996), there was correlation between high motivation levels of lecturers towards high levels of teacher social interaction on their job. Consequently, there is possibility that to promote students' achievement development the enhancement level of lecturers' motivation in teaching strategies is important.

In the teaching process, role of lecturers in ESP classroom should be well-established in every condition. The teachers should know their students' need as well as to meet students' future career. Hutchinson and Waters (1987) assert that ESP teachers should not become teachers of the subject matter, but rather students of the subject matter. They further explain that there is to be meaningful communication in the classroom, it will be a common fund of knowledge and interest between teacher and student. The teacher should also create interesting learning for the students to come up with the success of both sides for achieving the goals. In addition, 
creating a positive learning atmosphere is related with motivation; whereas, motivation is an important part of students'work that affects their future success or failure (Dornyei, 2001).

Dornyei (2001) stated that students' motivation has become one of the core issues of second or foreign language (L2) learning achievement in the last three decades and having attention to the nature and the role of L2 learning process. Due to the strong belief and to the growing of the importance of motivation for the learning of language, the researcher has focused her studies on lecturers' motivational strategies in classrooms. The prominent research about motivational strategy was done by Dornyei (1994) who developed motivation framework comprising several levels, language, learner, and learning situation levels.

The later study, Cheng and Dornyei (2007) formulated some items in motivational strategies which were grouped into four frameworks. The first framework is called establishing the basic motivational conditions. Furthermore, Dornyei (2011) explained that the absence of any motivation or motivational vacuum will reduce or even remove the success of motivational strategies implementation, which then affect the requirement to prepare precondition before some efforts to trigger effective motivations. The second framework is generating student motivation. Dornyei (2001) stated that the normally and ideally, a good language learner is triggered to learn since he is forced by their inner curiosity to know more and explore everything. Hence, they get learning experiences which stimulate their intrinsic pleasure constantly. The third framework is maintaning and protecting motivation. Dornyei (2001) said that an effective motivational repertoire should include motivation maintenance (or 'executive motivational) strategies. The last framework is encouraging positive self-evaluation. Dornyei (2001) said that students' amount of satisfaction toward accomplishments of certain duty was achieved after they complete the duty itself. So, the accomplishment of the task is very important for students.

Among some studies of motivation in language classroom, some have focused on motivational teaching strategies. Dornyei 
and Csizer (1998) conducted motivation research to motivate language learner in the area of L2. They concerned with the use of fifty one strategies and their using frequency in teaching practice by around two hundred English teachers from Hungarian who teach in some language institutions. According to their findings, they set the motivational macrostrategies into ten items to motivate the language learner which are mentioned as the following: Increase the learners'goal-orientedness, Set a personal example with your own behaviour, Create a pleasant, Personalize the learning process, Relaxed atmosphere in the classroom, Present the tasks properly, Develop a good relationship with the learners, Increase the learners'linguistic self-confidence, Make the language classes interesting, Create a pleasant, Promote learner autonomy, and Familiarize learners with the target language culture.

Furthermore, Cheng and Dornyei (2007) collaborated in the study concerning the use of motivational strategies employed by Taiwanese English teachers for motivating the students and research on the distinguished practices and beliefs between Hungarian and Taiwanese teachers. Cheng and Dornyei conducted their study in the Asian context. The finding showed that some strategies of motivation were influenced by specific culture. And also their findings, it was showed that universally promoted strategies in language learning classes are 'creating a pleasant classroom climate', 'displaying motivating teacher behaviour', 'presenting tasks properly', and 'promotinglearners' selfconfidence'.

Another research was held by Guilloteaux and Dornyei (2008) in South Korea on the influence of the lecturers' use of motivational strategies for teaching language in classroom. Both of them examined the link between the students' language learning motivations and the lecturers' motivational teaching practices. The conclusion stated that lecturers' motivational practice has the correlation with the increasing levels of the learners' motivation in learning behaviors as well as their motivational state.

Drawing on the aforementioned issues, this study aimed to examine teachers' motivational strategies and their reasons for the 
employment of the strategies in English for Specific Purposes (ESP) classrooms at the Faculty of Dakwah dan Ilmu Komunikasi (FDIK), the Faculty of Preaching and Communication Sciences at the Mataram State Islamic University (UIN Mataram).

\section{LITERATURE REVIEW}

The word "motivation" has been discussed many times by scholars, and one of the prominent scholars having massively published on this psychological state is Dornyei (2001). According to him, motivation will make people do something, keep continue to do it, and working hardly to achieve the objective of the job. Also he found that most successful L2 learners achieve high competence since they are motivated. It means that motivation play pivotal role for language learning. As has been stated previously, the approaches of researches on motivation have developed in many years. The idea of social psychological period, which was raised, by Robert Gardner and Wallace Lambert (1959-1990) stated that the L2 was not socioculturally neutral since it was affected by the culture which was associated with and the people's point of view towards it (Dornyei \& Ryan, 2015). The students' feeling in relation with the native speakers who teach the language affect the students' learning outcome. One of the most significant view points during the cognitive-situated period was that how the people think about oneself can affect someone's motivation and the stress shifted from the macro-perspective as in the communities to micro-perspectives such as in classrooms (Dornyei \& Ryan, 2015). Nowadays, people mention process-oriented period. It is characterized by the existence of motivation as a dynamic concept (Dornyei \&Ryan, 2015). The process model is understood as the perspective from which the researcher used to define the motivation in this research. In this model of motivation, the students have to first become motivated and their motivation will lead to the objectives of the learning. Furthermore, during the action, the motivation itself needs to be maintained and kept and when the task has been completed one has to assess the outcome (Dornyei, 2001). Motivation is influenced by the influences which 
means all events and thoughts which someone has in life and affect the motivational process (Dornyei, 2001).

The contradiction of being motivated is being unmotivated or demotivated. The word demotivation reefers to many things which may mean losing the motivation to achieve the goal. When the students feel unmotivated, it does not mean that they lose their understanding and concern on the issues that once motivated him or her but their demotivation feeling has become stronger than before (Dornyei, 2001). Many factors affecting students to be demotivated, some of them are attending embarrassing situation in a classroom, meeting with very strict lecturer, and having very stressful examination. Comparing to be demotivated, a motivation is not the result of the external factor that create demotivation, but it is really close to someone's feeling of inability or miss trust on self-ability to fulfill and finish the given task which possibly need to much work (Dornyei, 2001).

According to the study, Dornyei (2001) believed that most students' motivations are able to be increased. Furthermore, he mentioned that motivational strategies are the methods that a teacher can use to improve the students' motivation (Dornyei, 2015). The strategies can be found the research which was done by Dornyei and Otto's process oriented model (Dornyei, 2001). A teacher or lecturer must perform a way among various ways of motivational strategies which suit to learners or students in order to motivate the learners. In L2 learning context, the motivational strategies according to Dornyei (2001) are divided into four categories: 1) creating the basic motivational conditions, 2) generating initial motivation, 3) maintaining and protecting motivation and 4) encouraging positive retrospective selfevaluation. The example of creating the basic motivational conditions includes creating a comfortable and safe atmosphere in the classroom and formulating group rules. Generating initial motivation contains, for instance, improving students' attitudes towards the language and making it easier for them to succeed. Maintaining and protecting motivation could mean, for example, supporting students' self-reliance or developing learner autonomy. Encouraging positive retrospective self-evaluation involves among other issues giving positive feedback and prizes to learners. 
Muslimin, A. I., Lecturers' Motivational ...

\section{METHOD}

This study employs a descriptive qualitative research design on teachers' motivational strategies in ESP classrooms. In this point, the researcher deals mainly with making a detailed description of the features which exist in the data. Therefore, qualitative approach is considered as the research design of the present study. Latief (2011) defines qualitative research as the suitable way for a study which seeks to understand human behavior and the variables involved need to be observed and recorded verbally to be inductively analyzed. As a result, the data obtained are natural and free from the researcher's interference.

The present study is conducted in at faculty of dakwah and communication science (FDIK) of UIN Mataram. The English regular class (ESP class) are held based on the assigned schedules by the head of departments. The subjects of this study are four lecturers of ESP classes representing each departments at FDIK UIN Mataram. The departments are Management dakwah department, Islamic community development department, Islamic counseling guidance department, and Islamic communication and broadcasting department. The selection of the subjects for this study was based on the following criteria: (1) The lecturers teach in English classes (ESP class) in FDIK UIN Mataram. (2) The ESP lecturers had at least two years teaching experiences in teaching ESP and the selected lecturer has more years of teaching ESP experience in the selected department (if there is more than one ESP lecturer in the department) (3) the lecturers has been ever participated in an in-service training related with teaching ESP class. (4) They graduated from English Language Teaching Department Magister program. ESP lecturers at FDIK UIN Mataram is chosen as the participants of this study as they meet the aforementioned criteria. Therefore, the researcher asks for teachers willingnes to participate in the present study prior to the process of data collection.

The instruments is developed by the researcher herself. The researcher adopts expert validation to test the validity. The stages are as follow, first the researcher makes the observation protocol and interview list by herself, after that the expert will check the 
content of the instruments in detail. The instruments revision are done by the supervision of the expert to get the appropriate design. The expert is a senior lecturer of TEFL course at State University of Malang.

In order to get match assumption about teachers' motivational strategies in ESP classrooms, the researcher uses classroom observation as the first instrument which the blueprint is adopted from motivational strategy framework by Dornyei and Cheng (2007). The observation aims to complete the data related with the actual practices of teaching activity. This instrument is used to describe the information in the field and to find out which motivational strategies used by teachers in classrooms. The researcher becomes a passive observer who makes no interaction with the lecturers and students in the classroom to preserve a natural setting of the study. The interview is the second instrument to examine the lecturers' motivational strategies for their reasons to apply those strategies in classrooms.

The researcher utilizes video recording as the last instrument to record the strategies used by the teachers during their teaching sessions, which allows the researcher to keep record of and investigate the actual teaching performance of the teachers in detail. The information can help the researcher to track the teachers' motivational strategies that is actually happening in classrooms.

\section{FINDINGS AND DISCUSSION}

Grounded in the acquired data, it was found that the subjects of the research used all ten motivational strategies in motivational strategy framework as being proposed by Dornyei and Cheng (2007). However, among the ten motivational strategies framework, the most used in teaching ESP in classroom are creating basic motivational conditions in term of having proper teacher behavior, creating pleasant classroom environment, promoting group cohesiveness and group norms; generating students' motivation in term of increasing learners' goal orientedness; and maintaining and protecting motivation in term of 
promoting self-confident. While the moderate used of motivational strategies in teaching ESP in the present study are familiarizing learners with L2 related values, promoting learner autonomy, and making the learning task stimulating, Then, the least used motivational strategy in teaching ESP is presenting the task properly.

Based on the research about the scope of motivational strategies which was done by Taiwanese English teachers, in the research Cheng and Dörnyei (2007) showed some motivational strategies that are universally endorsed as being compared to his former research in Hungaria. The strategies include creating a pleasant classroom climate, displaying motivating teacher behaviour, presenting tasks properly, and promoting learners' selfconfidence. The same idea had been found in research conducted by Alshehri (2012) concerning perception of motivational strategies among Saudi EFL teachers and students through handling face to face and recorded interviews. It showed teacher behaviour, classroom atmosphere and task considered to be highly motivating. While in the present study, the three strategies (creating a pleasant classroom climate, displaying motivating teacher behaviour, and promoting learners' self-confidence) have similar characteristics as found in the present study. In contrary for presenting the task properly strategy, it does not belong to the most used strategy. Moreover, it became the only least used motivational strategy in teaching ESP in FDIK UIN Mataram.

Comparing the result of classroom observation in the subject class which is emphasized by the video recording and the result of the interview, there are some interesting facts: (1) some lecturers, individually, did not show similar condition using motivational strategies. For example: Lecturer 1 showed that he used promoting learner autonomy in his teaching performance in class but during the interview, he somehow not sure that promoting students' autonomy strategy needed to be used in class. Lecturer 3 did not promote group cohesiveness and group norms during his teaching performance though he was agree to use grouping strategy that possible for him to minimize the time consumption in assessment. (2) Lecturer 4 mentioned that students must have both intrinsic and extrinsic motivation. She helped her 
students to know it better by giving them motivation and knowledge. This situation pictured promoting self-motivating learner strategies which trigger students to push them do more to get their learning goal. It means that in the present study context, promoting self-motivating learner strategies existed. Then, this strategy has not been included in the observation protocol but it is existed in interview. (3) All lecturers depict proper lecturer behavior in the teaching performance as being noted by the researcher, but in the interview result, only lecturer 3 and 4 that dominantly provide the researcher proofs that they behave properly in teaching ESP.

Based on the understanding on the research situation, researcher found that those interesting facts might occur with possible situation: (1) the materials when the subjects of research was teaching was not appropriate to apply all strategies they were actually agree and had experienced to use it in teaching ESP, and (2) the curriculum in the university demanded lecturers to finished many materials in very limited time which hindered the their ideal teaching scenario in class.

In addition, it was founded that that the lecturers' reasons of considering certain motivational strategies used in ESP classrooms can be categorized as follows: (1) bringing teaching practicality and interaction to be easier, more comfortable, and being more fun, (2) creating students awareness on the future success, (3) showing their care on students' learning improvement and interest, and (4) being fair and wise in assessment.

Moreover, all lecturers in the present study have employed the motivational strategies although they were not having similar motivational indicators in their teaching ESP performance. But, they believed that motivational strategy had influenced the students' success in learning English and gave positive impacts as mentioned in their interview. Lecturer 1 said that when his students had successfully use their feeling, heart, and knowledge as well as being focus to understand the reading text as one of his student experienced. He found that student was helped a lot by his lecture motivation to believe on himself and be autonomy. In his term, lecturer 1 says "we should humanize human". Lecturer 2 mentioned that many of her students came and asked about 
English. Further she found that pleasant learning environment and recognizing students' effort with appropriate feedback really improve students' writing skill. Lecturer 3 found that by his motivation which made students understood on future challenges, he greatly trigger his students' spirit to learn more English through class and having extra English courses. This finding supports the previous research which was conducted by Alshehri (2012) concerning perception of motivational strategies among Saudi EFL lecturers and students through handling face to face and recorded interviews. The finding of the study, the same ideas about lecturer behaviour, classroom atmosphere and task considered to be highly motivating theme both lecturer and student. Also, bringing motivational strategies to ESP class, as his experienced to doing different teaching technique, the students' participation and learning achievement have improved significantly. Lecturer 4 stated that after she encouraged students to be confident and did not think a lot on mistakes they made, many students were eager to come forward competing to answers the task by writing on the white board or even having presentation in front of the class. She got feedback from her students that they were help a lot by her ways of teaching that presenting task properly in reading text, leading them to be autonomous learner by guidance to find the core of text as well as difficult words through context clues, are really helpful for them till they do not need to be dependence to English dictionary while they were reading English references outside of ESP class.

All of those significances are in correspondence with some previous research findings, such as that of Guilloteaux and Dornyei (2008) who investigated the the influence of the lecturers' use of motivational strategies in English language classroom in South Korea. The results proposed that lecturers' motivational practice increased the learners' motivated learning behaviors as well as their motivational state. Also, a research carried out by Bernaus and Gardner (2009), it mentioned that lecturers' motivations and strategies use in the classroom give positive influence to students' motivation and their achievements in learning English.

In line with the lecturers' consideration in using the above motivational strategies as explained in the previous chapter, each 
lecturer had found that what they had done gave positive impacts to the success of their ESP teaching and students.

\section{CONCLUSION}

Based on findings and discussion of this research, the conclusion is that ESP lecturers in FDIK UIN Mataram generally employed all the ten commandments to motivate English language learners in ESP Classrooms as promoted by Cheng and Dörnyei (2007), namely creating a pleasant and relaxing atmosphere in the classroom, setting a personal example with their own behaviour, promoting group cohesiveness and norms, presenting the tasks properly, increasing the learners'linguistic self-confidence, making the language classes interesting, personalizing the learning process, increasing the learners'goal-orientedness, familiarizing learners with the target language culture, and promoting learner autonomy. Then, researcher found additional motivational strategy that appear in lecturer no 3 interview that is not belong to the ten commandment but also stated in Cheng and Dörnyei (2007) main instrument, it is promoting self-motivating learner strategy.

In addition, among the ten motivational strategies framework, the most used in teaching ESP in classroom are creating basic motivational conditions in term of having proper lecturer behavior, creating pleasant classroom environment, promoting group cohesiveness and group norms; generating students' motivation in term of increasing learners' goal orientedness; and maintaining and protecting motivation in term of promoting self-confident. While the moderate used of motivational strategies in teaching ESP in the present study are promoting learner autonomy, making the learning task stimulating, and familiarizing learners with L2 related values. Then, the least used motivational strategy in teaching ESP is presenting the task properly.

Related to the second research problem, the reasons why the lecturers consider to use those motivational strategies are: (1) bringing teaching practicality and interaction to be easier, more comfortable, and being more fun, (2) creating students' awareness on the future success, (3) showing their care on students' learning 
Muslimin, A. I., Lecturers' Motivational ...

improvement and interest, and (4) being fair and wise in assessment. Then, in line with the lecturers' consideration in using the above motivational strategies as explained in the previous chapter, each lecturer had found that what they had done gave positive impacts to the success of their ESP teaching and students

\section{REFERENCES}

Alshehri, E. (2012). Saudi EFL lecturers' and students' perception of motivational strategies. The Lancaster University Postgraduate Conference in Linguistics and Language Teaching.

Bishay, A. (1996). Lecturer motivation and job satisfaction: a study employing the experience sampling method. Journal of Undergraduate Science, 3. 147-154.

Cheng, H. F., \& Dornyei, Z. (2007). The use of motivational strategies in language instruction: the case of EFL teaching in taiwan. Innovation in Language Learning and Teaching, 1(1), 153-173.

Day, J., \& Krzanowski, M. (2011). Teaching english for specific purposes: An introduction. New York: Cambridge University Press.

Dornyei, Z., \& Csizer, K. (1998). Ten commandmentsfor motivating language learners: results of an empirical study. Language Teaching Research, 2(3), 203-229.

Dornyei, Z. (2007). Motivation in action: Towards a processoriented conceptualisation of student motivation. British Journal of Educational Psychology, 70, 519-538.

Dörnyei, Z. (2001). Motivational strategies in the language classroom. Cambridge University Press.

Dörnyei, Z., \& Ryan, S. (2015). The psychology of the language learner revisited. New York: Routledge.

Eggleton, P. J. (1992). Motivation: A Key to Effective Teaching. retrieved from math.coe.uga.edu/TME/Issues/v03n2/Eggleton.pdf

Guilloteaux, M. J., \& Dornyei, Z. (2008). Motivating language learners: A classroom-oriented investigation of the effects of motivational strategies on student motovation. Tesol Quarterly, 42(1), 55-77. 
Hutchinson, T., \& Waters, A.. (1987). English for Specific Purposes: A Learning Centered Approach. New York: Cambridge University Press.

Latief, M. A. (2011). Research methods on language learning. An introduction. Malang: UM Press. 